Gut, 1984, 25, 398-404

\title{
Treatment of instrumental oesophageal perforation
}

\author{
I C E WESDORP, J F W M BARTELSMAN, K HUIBREGTSE, \\ F C A DEN HARTOG JAGER, AND G N TYTGAT
}

\begin{abstract}
From the Department of Medicine, Academic Medical Centre, Division of Gastroenterology, Amsterdam, Netherlands
\end{abstract}

SUMMARY Results of a conservative approach in the treatment of instrumental oesophageal perforation were evaluated in 54 patients. The perforations occurred either during introduction of/or manipulation with fibre-endoscopes (six), during dilatation procedures with metal olives (five), mercury bougies (six) or during pneumodilatation (two) in 19 patients without malignancy and during an intubation procedure of a plastic prosthesis in 35 patients with an inoperable malignant oesophageal narrowing. In the majority of patients $(94.4 \%)$ the diagnosis of oesophageal perforation was made within two hours. Conservative treatment consisted of nothing by mouth, antibiotics and naso-oesophageal suction. Of the 19 patients without malignancy, 14 were treated conservatively and five by surgery (primary closure and drainage) with no deaths. All patients with an oesophageal perforation caused by palliative intubation received conservative treatment with three deaths $(8 \cdot 6 \%)$. Non-surgical treatment of instrumental oesophageal perforation is feasable and acceptable, provided the perforation is detected early, before major contamination has occurred and is indicated in case of perforation in patients with malignancy.

Instrumental oesophageal perforation is a life threatening condition. In most cases the injury to the oesophageal wall occurs during introduction of various instruments, during dilatation procedures, when attempting to pass a narrow stenosis, during extraction of a foreign body, or during the palliative intubation of the gullet with an endoprosthesis. There is universal agreement that early diagnosis and treatment are essential but controversy still exist about the best method of treatment. As a rule, direct surgical intervention is said to be indicated in all types of oesophageal perforation. Various procedures may be considered, such as drainage with or without primary closure, oesophageal exclusion, or even oesophagectomy. A non-surgical approach is advocated by only a minority of authors and then limited in most cases to patients with a highly located perforation or restricted to elderly poor risk patients. Both methods of treatment have a mortality rate up to $30 \%$ even when early (within 12 hours) intervention is carried out. ${ }^{1-5}$ The mortality rises dramatically when appropriate

Address for correspondence: Prof Dr G N Tytgat. Academic Medical Centre. Department of Medicine. Division of Gastroenterology, Meibergdreef 9, 1105 AZ Amsterdam. The Netherlands.

Received for publication 18 July 1983 treatment is delayed. ${ }^{5-9}$ Mortality is also said to be related to the cause, ${ }^{59}$ the localisation, ${ }^{56810}$ and the contamination of the perforation site.

For many years we have adopted a conservative approach in the treatment of instrumental oesophageal perforation except for very large tears or subdiaphragmatic ruptures in young patients with a benign condition. The results obtained confirm that the majority of perforations can be handled non-surgically, provided such complications are detected early and provided major contamination, especially with food, of the perforation site has been prevented.

In view of the discrepancies in the literature regarding a conservative approach, and because of our impression that many physicians lack confidence with medical treatment in this situation, we would like to contribute to the existing medical knowledge by presenting our experience with medical therapy in a large consecutive group of patients with oesophageal perforation, diagnosed at our unit.

\section{Methods}

PATIENTS

We evaluated 54 consecutive unselected patients 398 
with instrumental oesophageal perforation during the period between 1973 and 1982. These perforations occurred either during introduction of/or manipulation with fibre-endoscopes, during dilatation procedures with metal olives, ${ }^{11}$ mercury bougies or during pneumatic dilatation, and during insertion of a plastic prosthesis.

\section{DIAGNOSIS}

At our unit patients are kept under surveillance until free from pain after any oesophageal instrumentation. A few sips of water are then allowed, and if discomfort persists or reoccurs investigation for possible perforation is immediately carried out. As a rule all intubated patients are monitored closely including a routine radiograph of the chest immediately after the procedure. The diagnosis of instrumental oesophageal perforation was made in nearly all patients by standard radiology. Careful attention was given to abnormalities of the chest radiograph, varying from a thin prevertebral streak of air (Fig. 1) to obvious subcutaneous emphysema, pneumomediastinum or pneumoperitoneum. In some patients with suspected perforation despite a normal chest $\mathrm{x}$-ray picture, the laceration was always visualised by extravasation of water soluble contrast material (Fig. 2). The perforation was diagnosed endoscopically in patients with a malignant oesophageal narrowing during the intubation of a plastic prothesis, and in one patient after perforation of a Zenkers diverticulum.

\section{TIME OF DETECTION}

In 51 patients, the diagnosis was made within one to two hours after occurrence, while in three patients there was a delay: six hours in a patient after pneumodilatation, and 24 hours in two patients after an intubation procedure. This delay was caused by

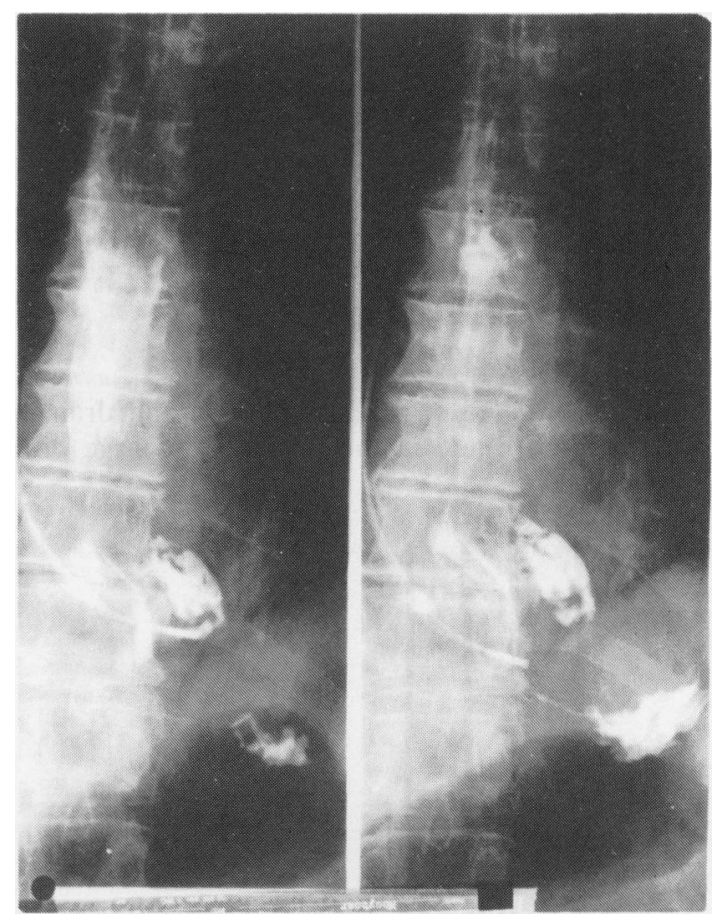

Fig. 2 Extravasation of contrast localising perforation site at level of tip of visible pacemaker thread (normal chest $x$-ray picture).

the late onset of symptoms and by initial normal findings on the chest radiograph shortly after instrumentation.

\section{CONSERVATIVE TREATMENT}

The conservative treatment consisted of nothing by mouth, antibiotics, intravenous hydration, and
Fig. 1 Radiograph showing thin prevertebral streak of air after perforation of pyriform sinus with extravasation of contrast at the perforation site.

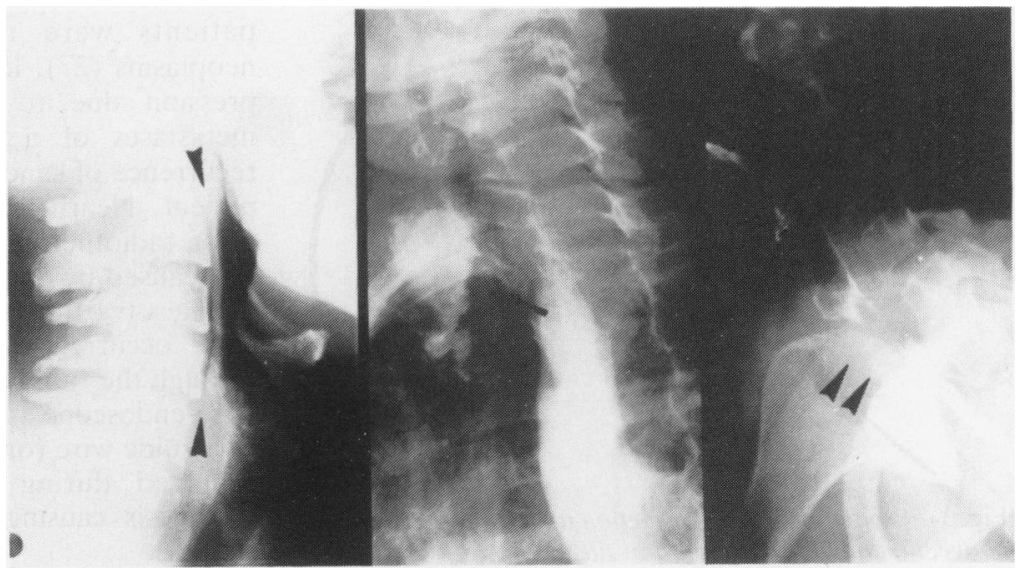


alimentation and naso-oesophageal suction using a tube with multiple side holes, placed in such a way that the side holes were placed above, at, and below the perforation site (Fig. 3). If necessary, a second tube ending distally beyond the pylorus was glued to the suction tube. ${ }^{12}$ This regimen was continued for at least five to seven days. After this period a control oesophagogram with water soluble contrast was made to exclude ongoing extravasation.

\section{SURGICAL TREATMENT}

Surgery consisted of primary closure and drainage and was performed in the presence of large distal

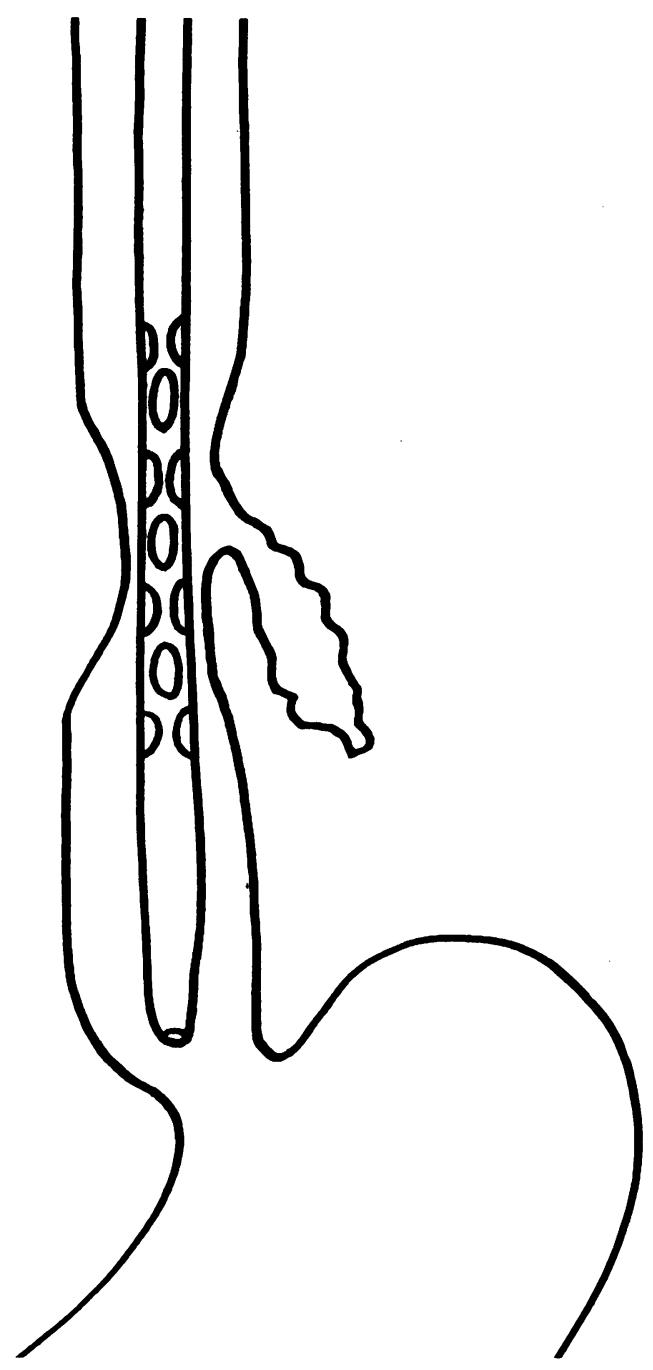

Fig. 3 Proper placement of suction tube with side holes above, at, and below perforation site. (subdiaphragmatic) perforations especially in younger patients without malignancy, and in cases of suspicion of major contamination of the perforation site.

For the evaluation of the results a distinction was made between patients with oesophageal perforations caused by diagnostic or therapeutical instrumentation without malignancy (non-malignant group), and patients with a perforation caused by a palliative intubation procedure in case of inoperable malignant oesophageal narrowing (malignant group).

\section{Results}

PATIENTS CHARACTERISTICS

The characteristics of the patients (24 men, 30 women, age range $31-87$ years) are summarised in Table 1.

The instrumental perforation in the nonmalignant group of 19 patients occurred most often during a dilatation procedure (13), while in six patients a perforation occurred during a diagnostic endoscopy. A highly located perforation (pyriform sinus, two; Zenkers diverticulum, three) occurred in five patients during instrumental introduction. Two patients with severe mid-oesophageal caustic stenosis were perforated despite utmost care being taken during diagnostic endoscopy respiratory dilatation. The distally located oesophageal perforations occurred during dilatation with metal olives or mercury bougies of radiation (two), peptic (five), or anastomotic (two) strictures. In one patient a perforation of a Schatzki ring presumably occurred during a smooth uneventful routine diagnostic ERCP and distal laceration of the oesophagus occurred during pneumodilatation in two patients with vigorous achalasia.

As can be seen from Table 1, indications for intubation in the more elderly malignant group of 35 patients were inoperable cardio-oesophageal neoplasms (27), local narrowing by extrinsic compression due to bronchial carcinoma (five) or metastases of a pulmonary tumour (two), and recurrence of cancer after previous resection in one patient. Nearly half of the patients had received prior radiotherapy. In 30 patients the perforation was caused by dilatation (metal olives, 28; mercury bougies, two); in three patients the perforation must have occurred during attempts to find a path through the tumour mass either with a small calibre fibre-endoscope (one), a coagulation probe (one), or a guide wire (one). In two patients, a perforation occurred during replacement of a respiratory prosthesis causing a faussé route in one patient (Fig. 4). 
Table 1 Summary of 54 patients

\begin{tabular}{|c|c|c|c|c|c|c|c|c|}
\hline Non-malignant group & $\begin{array}{ll}\text { Patients } & \\
\text { (no) } & M \\
19 & 7\end{array}$ & $\begin{array}{l}F \\
12\end{array}$ & $\begin{array}{l}\text { Mean } \\
\text { age }(y r) \\
59.2\end{array}$ & Malignant group & $\begin{array}{l}\text { Patients } \\
\text { (no) } \\
35\end{array}$ & $\begin{array}{l}M \\
17\end{array}$ & $\begin{array}{l}F \\
18\end{array}$ & $\begin{array}{l}\text { Mean } \\
\text { age (yr) } \\
68.4\end{array}$ \\
\hline $\begin{array}{l}\text { Localisation } \\
\text { perforation }\end{array}$ & Instrumentation & & $\begin{array}{l}\text { Patients } \\
\text { (no) }\end{array}$ & $\begin{array}{l}\text { Localisation } \\
\text { perforation }\end{array}$ & Instrumentation & & $\begin{array}{l}\text { Patients } \\
\text { (no) }\end{array}$ & $\begin{array}{l}\text { Prev. } \\
\text { radio- } \\
\text { therapy }\end{array}$ \\
\hline Pyrif sinus & $\begin{array}{l}\text { Merc bougie } \\
\text { Fibre-endosc }\end{array}$ & - & $\begin{array}{l}1 \\
1\end{array}$ & $\begin{array}{l}\text { Mid ocsoph } \\
\text { (Ocsoph ca) }\end{array}$ & $\begin{array}{l}\text { Fibre-endosc } \\
\text { Coagul probe }\end{array}$ & & $\begin{array}{l}1 \\
1\end{array}$ & $\begin{array}{l}1 \\
0\end{array}$ \\
\hline Oesoph divert & Fibre-endosc & & 3 & & Guide wire & & 1 & () \\
\hline Caust stenos & Fibre-endosc & & 1 & & Metal olive & & 6 & 5 \\
\hline & Metal olive & & 1 & & Merc bougic & & 2 & () \\
\hline Radiat stenos & Metal olive & & 1 & & Prosthesis & & 1 & 1 \\
\hline & Merc bougie & & 1 & Mid oesoph & & & & \\
\hline Peptic stenos & Metal olive & & 2 & (Extr compr) & Metal olive & & 7 & 5 \\
\hline & Merc bougie & & 3 & Low oesoph & Metal olive & & 14 & () \\
\hline Schatzki ring & Fibre-endosc & & 1 & (Cardia ca) & Prosthesis & & 1 & 1 \\
\hline Anastom stenos & Metal olive & & 1 & Low ocsoph & & & & \\
\hline & Merc bougic & & 1 & (Anast recurr ca) & Metal olive & & 1 & () \\
\hline Achalasia & Pneumatic & & 2 & & & & & \\
\hline
\end{tabular}

TREATMENT RESULTS

The results of treatment and the final outcome are summarised in Table 2 . In the non-malignant group of 19 patients, 14 were treated conservatively and five by surgery, while all 35 patients with a perforation caused by a palliative insertion of a prosthesis were treated conservatively.

NON-MALIGNANT GROUP

The conservatively treated patients had high, mid and low or subdiaphragmatic oesophageal perforations. All medically treated patients usually recovered within one week; five received further uneventful dilatations because of recurrent stricturing except for one young woman with a severe caustic stenosis, who was perforated a second time one month later, in an attempt to dilate her stricture with mercury bougies. She was again treated medically with success and again dilated afterwards. Also the patients with a conservatively
Fig. 4 Radiograph showing a malignant oesophageal narrowing with faussé route caused by replacement of prosthesis and control oesophagogram after recovery with prosthesis in situ.

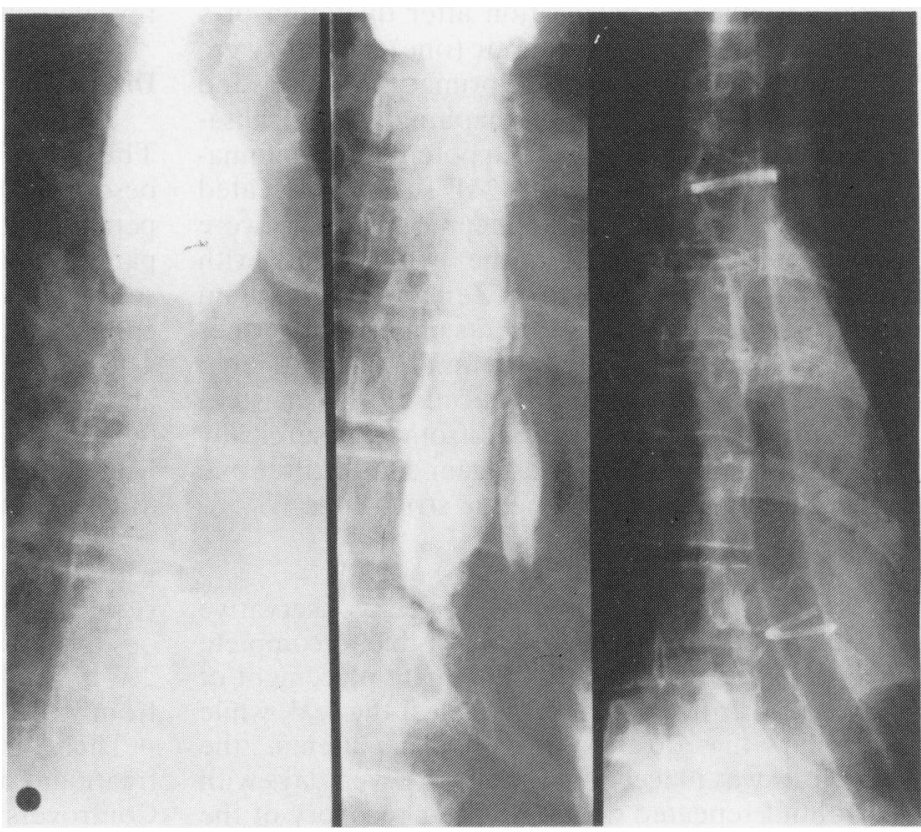


Table 2 Treatment results instrumental oesophageal perforation in 54 patients

\begin{tabular}{|c|c|c|c|c|c|}
\hline $\begin{array}{l}\text { Localisation } \\
\text { perforation }\end{array}$ & $\begin{array}{l}\text { Conseriative } \\
\text { treatment }\end{array}$ & Follow up & $\begin{array}{l}\text { Surgical } \\
\text { treatment }\end{array}$ & Follow up & Deaths \\
\hline \multicolumn{6}{|c|}{ Non-malignant group ( 19 patients) } \\
\hline Pyrif sinus & 2 & $\begin{array}{l}\text { Dilat (1) } \\
\text { (peptic st) }\end{array}$ & () & - & () \\
\hline Oesoph divert & 2 & Dilat (()) & 1 & $\begin{array}{l}\text { Pn dilat (1) } \\
\text { (achalasia) }\end{array}$ & () \\
\hline Caust stenos & 2 & Dilat (2) & 0 & 一 & () \\
\hline Radiat stenos & 2 & Dilat $(0)$ & 0 & - & () \\
\hline Peptic stenos & 3 & Dilat (2) & 2 & $\begin{array}{l}\text { Fundopl (1) } \\
\text { Dilat (1) }\end{array}$ & () \\
\hline Schatzki ring & 1 & Dilat $(0)$ & 0 & - & 0 \\
\hline Anast stenos & 1 & Dilat $(0)$ & 1 & Roux-Y & () \\
\hline Achalasia & 1 & Pn dilat (1) & 1 & Pn dilat (1) & 0 \\
\hline \multicolumn{6}{|c|}{ Malignant group ( 35 paticnts) } \\
\hline \multicolumn{6}{|c|}{ Conservative treatment: } \\
\hline \multicolumn{4}{|c|}{ Including direct intubation of prosthesis } & 10 & 2 \\
\hline \multicolumn{4}{|c|}{ Later intubation of prosthesis after recovery } & 24 & () \\
\hline \multicolumn{4}{|c|}{ No intubation after dilatation } & 1 & 1 \\
\hline
\end{tabular}

treated perforation caused by pneumodilatation. received further pneumodilatations without problems. Five patients in the non-malignant group were treated surgically. Two patients had a large oesophageal tear, immediately diagnosed endoscopically (visible pleural cavity) in case of perforation of a Zenkers diverticulum and radiologically (massive extravasation) six hours after pneumodilatation, for which we were uncertain whether or not contamination had occurred. Both these patients were treated surgically the same day by primary closure and drainage. Three patients with distal oesophageal perforation after dilatation of a peptic (two) and an anastomotic (one) stricture were also treated surgically by primary closure and drainage because of the subdiaphragmatic localisation of the perforation site with potential contamination of the peritoneal cavity. All surgically treated patients recovered. Further pneumodilatations were carried out successfully in the two patients with achalasia (one patient with a Zenkers diverticulum also had achalasia). Two patients underwent further surgical procedures later on (fundoplication, one: Roux-y anastomosis, one) because of persistent stricturing, while one patient from the surgically treated group of patients was again dilated after one year because of recurrent peptic stricturing.

\section{MALIGNANT GROUP}

All the malignant patients received conservative treatment. In 10 patients it was possible to complete the intubation procedure by adequate placement of the prosthesis hoping thereby to seal the leak while bypassing the obstruction. In 24 patients, the prosthesis was placed within four to seven days with or without repeated dilatation after recovery of the patient. There were three deaths in this group: we decided to abstain after the consulting the family, from further final treatment in an 86 year old cachectic woman, immediately after the diagnosis of perforation was made. An 80 year old woman died a few hours after successful intubation because of aspiration. A 55 year old man died six days after the intubation of a prosthesis because of mediastinitis with abscess formation, unquestionably related to delayed (after 24 hours) detection of the perforation. Initially, this patient had been essentially pain free and control x-ray picture had not revealed any extravasation.

\section{Discussion}

There are different causes for iatrogenic oesophageal perforation, varying from blunt or penetrating trauma, to ingestion of foreign bodies, paraoesophageal surgery and most frequently endoscopical instrumentation. Modern diagnostic endoscopy rarely causes oesophageal perforation. The reported incidence for rigid oesophagoscopy is about $0.11 \% \%^{13}$ and for fibre-endoscopy varies from $0 \cdot 018-0.03 \% .^{1+15}$ Such perforation usually occurs with difficult intubations, inexperienced operators and elderly frail patients with distorted anatomy. ${ }^{1+16}$ Therapeutic endoscopy is associated with a much higher frequency of perforation. The reported incidence amounts to $0.9 \%$ for oesophageal dilatation of strictures, ${ }^{1+15}$ varies from $2 \%$ to $5 \%$ for pneumodilatation of achlasia ${ }^{17-14}$ and from $7.9 \%$ to $11 \%$ for palliative intubation. ${ }^{1+20} 21$

There is universal agreement that immediate treatment of oesophageal perforation is mandatory. Controversy, however, exists regarding the appro- 
priate approach of such patients. When reviewing the literature about treatment of iatrogenic and especially instrumental perforations one is faced with the problem of exact interpretation, because oesophageal perforations of different aetiology (even spontaneous) are put together for evaluation of treatment results. Furthermore no or insufficient information is given about the time of detection or the presence of contamination of the perforation site before treatment started. Since the first successful closure of an oesophageal perforation by Barrett in $1947,{ }^{22}$ immediate surgical intervention is advocated in most reports, $\left.{ }^{6-8} 10\right)^{23-25}$ most editorials, ${ }^{26} 27$ and textbooks ${ }^{92-30}$ in the case of nearly all types of oesophageal perforation, with a mortality rate amounting up to $30 \%$ in case of early (within six to 12 hours) treatment. ${ }^{15}$ Much less attention is given to conservative treatment of oesophageal perforation. Analysis of such studies is even more difficult because of wide variability in patient selection and in treatment modalities, including nothing per os, antibiotics, naso-oesophageal/gastric suction, and even (limited) thoracotomy, gastrostomy, and jejunostomy. ${ }^{31}$ This presumably explains the even greater variation in treatment results with a mortality rate varying from $0 \%$ to $84 \%$. $^{35} 1032-35$

We feel that there is a difference between endoscopical instrument perforation and other oesophageal perforations because the lesions occurring during endoscopical instrumentation are usually recognised immediately, or soon after occurrence, and are therefore detected in an early stage before major contamination has occurred. This fact is mainly responsible for a lower mortality rate after instrumental perforations fluctuating around $12 \%,{ }^{5}$ compared with that obtained in other types of oesophageal perforations. Mengoli and Klassen ${ }^{33}$ reported an even lower mortality rate of $6 \%$ in case of conservative treatment of patients with only instrumental oesophageal perforations. The purpose of our study was to find out whether a conservative approach is justified in those cases where instrumental perforation is detected early and when contamination has presumably been avoided.

In our patients, the diagnosis of oesophageal perforation was made within two hours in $94.4 \%$. This is largely because the physicians in training were aware of symptoms and signs of oesophageal perforation and due to careful observation after any difficult endoscopical procedure. A most important concern for the physician in care is the avoidance of contamination of the perforation site. We feel that the chance of contamination can be reduced with a properly positioned and properly functioning nasooesophageal suction tube, which in addition may speed up closure of the perforation site.
The results of this analysis confirm the feasibility and acceptability of our current therapeutic approach in cases of perforation. All non-malignant patients with instrumental perforation treated conservatively survived. Also all non-malignant surgically treated patients recovered. The $0 \%$ mortality rate in this non-malignant group is largely because the lesions were detected early before major contamination of the perforation site had occurred. In the group of patients with malignancy, conservative treatment resulted in a good result in 32 of 35 patients $(91.4 \%)$. The three deaths observed were caused by a combination of poor clinical condition of the patient (abstention), additional complication of the procedure (aspiration), and delay in detection of the perforation (mediastinitis and mediastinal abscess formation). The mortality rate of $8.6 \%$ in the malignant group is low compared with other results of conservative treatment of oesophageal perforations caused by palliative intubation with a reported mortality up to $33.3 \% .^{21}$

Many patients received further dilatation with or without intubation within one week after perforation indicating the fast healing tendency even of a tear of cancerous invaded tissue. From these results we may conclude that a non-surgical approach in case of instrumental oesophageal perforation is indeed feasible and perferable, provided the perforation is detected early (within 12-24 hours) before major contamination has occurred and provided adequate aspiration across the perforation is possible. Non-surgical treatment is the treatment of choice in case of a perforation in patients with malignancy with or without previous radiotherapy because such patients are often unfit for major surgery such as resection and reconstruction due to inoperability, severe inanition, and general debility. Surgical treatment is probably still preferable for large subdiaphragmatic perforation especially in young patients and/or in case of obvious contamination of the perforation site.

\section{References}

1 Berry BE, Ochsner JL. Perforation of the esophagus. A 30 year review. J Thorac Cardiovasc Surg 1973; 65: $1-7$.

2 Ghosh BC, Chaudry KU, Beattie EJ Jr. Perforation of the esophagus. Surg Gynec Obstet 1972; 135: 729-31.

3 Goldstein LA, Thompson WR. Esophageal perforation: a 15 year experience. Am J Surg 1982; 143: 495-503.

4 Keszler P, Buzna E. Surgical and conservative 
management of esophageal perforation. Chest 1981; 80: $158-62$.

5 Bergdahl L. Henze A. The treatment of oesophageal perforations. Scand J Thorac Cardiovasc Surg 1978: 12: 137-41.

6 Sandrasagra FA. English TAH, Milstein BB. The management and prognosis of oesophageal perforation. Br J Surg 1978; 65: 629-32.

7 Skinner DB. Little AG, DeMeester TR. Management of esophageal perforation. Am J Surg 1980: 139: 760-4.

8 Wichern WA Jr. Perforation of the esophagus. $A m J$ Surg 1970; 119: 534-6.

9 Postlethwait RW. Perforation and rupture. In: Postlethwait RW, ed. Surgery of the esophagus. New York: Appleton-Century-Crofts, 1979: 152-76.

10 Sawyers JL. Lane CE, Foster JH, Daniel RA. Esophageal perforation. Ann Thorac Surg 1975: 19: 233-8.

11 Lilly JO, McCaffrey TD Jr. Esophageal stricture dilatation: a new method adapted to the fibreoptic esophagoscope. Am J Dig Dis 1971; 16: 1137-40.

12 Mathus-Vliegen EHM, Tytgat GN. The role of endoscopy in the fast and correct positioning of feeding tubes. Endoscopy 1984. (In press.)

$13 \mathrm{Katz}$ D. Morbidity and mortality in standard and flexible gastrointestinal endoscopy. Gastrointest Endosc 1967: 14: 134-7.

14 Dawson J. Cockel R. Oesophageal perforation at fibreoptic gastroscopy. Br Med J 1981; 283: 583.

15 Silvis SE, Nebel O, Rogers G, Sugawa $C h$. Mandelstam P. Endoscopic complications: result of the 1974 American Society of Gastrointestinal Endoscopy Survey. JAMA 1976: 235: 928-30.

16 Wesdorp ICE. Bartelsman JFWM, Den Hartog Jager FCA, Huibregtse K. Tytgat GN. Results of conservative treatment of benign esophageal strictures: a follow-up study in 100 patients. Gastroenterology 1982: 82: 487-93.

17 VanTrappen G, Hellemans J. Treatment of achalasia and related motor disorders. Gastroenterology 1980) 79: $144-54$.

18 Sanderson DR, Ellis EH, Olson AM. Achalasia of the esophagus: results of therapy by dilatation. Chest 197(): 48: $116-21$.

19 Bennet JR. Hendrix TR. Treatment of achalsia with pneumatic dilatation. Mod Treat 1970; 7: 1217-28.

20) Den Hartog Jager FCA. Bartelsman JFWM. Tytgat
GN. Palliative treatment of obstructing esophagogastric malignancy by endoscopic positioning of a plastic prosthesis. Gastroenterology 1979; 77: 1008-14.

21 Ogilvie AL, Dronfield MW, Ferguson R, Atkinson M. Palliative intubation of oesophagogastric neoplasms at fibreoptic endoscopy. Gut 1982; 23: 1060-7.

22 Barrett NR. Report of a case of spontaneous perforation of the oesophagus successfully treated by operation. Br J Surg 1947; 35: 216-8.

23 Triggiani E. Belsey R. Oesophageal trauma: incidence. diagnosis and management. Thorax 1977; 32: 241-9.

24 Banks JG, Bancewicz J. Perforation of the oesophagus: experience in a general hospital. Br J Surg 1981; 68: $580-4$.

25 Janssen $\mathrm{C} \mathrm{Jr}$. Perforation of the intrathoracic oesophagus. Scand J Thorac Cardiovasc Surg 1976; 10: 189-92.

26 Editorial. Management of oesophageal perforation. $\mathrm{Br}$ Med J 1977; 2: 540.

27 Editorial. The leaking oesophagus. Lancet 1977; 2: 692-3.

28 Pope CE II. Involvement of the esophagus by infections, systemic illnesses, and physical agents. In: Sleisenger MH. Fordtran JS, eds. Gastrointestinal disease. Philadelphia/London/Toronto: W B Saunders, 1978: 592-6(1)4.

29 Savary M. Miller G. The diseased esophagus. In: Savary M. Miller G. eds. The esophagus. Solothurn: Gassmann. 1978: 91-239.

30 Atkins JP Jr. Atkins JP. Esophageal perforations and trauma. In Bockus HL, ed. Gastroenterology. Philadelphia/London/Toronto: W B Saunders, 1974: 344-8.

31 Lyon WS. Seremetis MG. DeGuzman VC. Peabody JW Jr. Ruptures and perforations: the case for conservative supportive management. Ann Thorac Surg 1978: 25: 346-5().

32 Inberg MV. Manner R. Puhakka H. Management of instrumental and spontaneous (atraumatic) perforation of the esophagus. Scand J Thorac Cardsiovasc Surg 1971: 5: 61-6.

33 Mengoli LR. Klassen KP. Conservative management of esophageal perforation. Arch Surg 1965; 91: 238-40.

34 Neuhof H. Jemerin E. Results of treatment of perforation of the esophagus. Ann Surg 1948: 128: 971-5.

35 Wolloch Y, Zer M. Dintsman M. Iatrogenic perforations of the esophagus. Therapeutic considerations. Arch Surg 1974: 108: 357-60. 